\title{
Maestros y maestras en la narrativa de Posguerra y Democracia (imágenes didácticas de lectura y escritura)'
}

\author{
Literacy Teachers in the Narrative of the Spanish Postwar \\ (Reflections on Reading Education's)
}

FERMÍN EZPELETA AGUILAR

Universidad de Zaragoza

España

ferminez@unizar.es

(Recibido I7-O7-20I4; aceptado I2-05-20I5)

Resumen. La narrativa española suministra al investigador material valioso acerca de las prácticas educativas de la escuela primaria de determinados momentos históricos del siglo $X X$. A partir de un corpus de unas cuarenta obras publicadas entre 1939 y 2005 , que contienen personajes maestras o maestros y que inciden de modo especial en la enseñanza de la lectura y la escritura de los escolares, se tratará de mostrar cómo son percibidos por los escritores unos usos didácticos que surgen a partir del currículo de enseñanza primaria. Cruzados todos estos datos, y observados en el panorama, aportarán claves para entender aspectos de la historia de la enseñanza de las primeras letras en las sucesivas generaciones que recibieron instrucción desde los años de la Segunda República hasta 1975.

Palabras clave: Maestros, novela española de posguerra, didáctica, leer, escribir.
Abstract. Spanish narrative provides the researcher valuable material about educational practices of elementary school in historical moments of the twentieth century. From a corpus of about forty works published between 1939 and 2005, we will try to show how the educational uses of reading and writing are perceived by the writers. Crossed all these data, and seen in the picture, they will provide keys to understanding aspects of the history of the teaching of the first letters in successive generations who were educated since the years of the Second Republic until 1975.

Keywords: School teachers, Spanish postwar novel, teaching, reading, writing.

\footnotetext{
${ }^{\text {I }}$ Para citar este artículo: Ezpeleta Aguilar, Fermín (2OI5). Maestros y maestras en la narrativa de Posguerra y Democracia (imágenes didácticas de lectura y escritura). Alabe 12. [www.revistaalabe.com]

DOI: IO.I5645/Alabe.20I5.I2.7
} 


\section{I - Introducción ${ }^{2}$}

La narrativa española a partir de la posguerra acoge abundante material testimonial sobre las figuras del maestro y maestra de escuela, en tanto que personajes con rica tradición literaria que se prestan en el nuevo contexto a tratamientos realistas, pues conceptos como escuela y educación difícilmente pueden sustraerse como temas de fondo a las distintas promociones de novelistas de ese periodo ${ }^{3}$. Naturalmente los autores en estas ideaciones literarias se harán eco de la cuestión de la lengua española en sus primeros estadios: la lectura y la escritura, como prácticas que quintaesencian el problema de la educación, glosadas en ocasiones desde el punto de vista didáctico.

En cuanto a los subgéneros que sirven de receptáculo a este tipo de narraciones, sigue siendo operativo un modelo como el de la novela autobiográfica de colegios, que había alcanzado su plenitud en la narrativa novecentista, y que encuentra ahora alguna continuación esporádica en novelas como Mari Sol, maestra rural (I944) de Josefina Álvarez de Cánovas, o de Juan Eslava Galán, Escuela y prisiones de Vicentito González (2000). El subgénero de memorias anoveladas puede funcionar también como cauce de relato de vivencias de la etapa escolar de autores Xosé Neira Vilas en Memorias dun neno labrego (i96I, en gallego).

Pueden recogerse asimismo experiencias de los propios docentes, maestros, que enriquecen con sus narrativas el viejo formato de novelas pedagógicas profesionales. Es el caso de Diario de una maestra (I96I) de Dolores Medio, de Historia de una maestra (I990) de Josefina Aldecoa u otras narraciones adscritas también a la corriente del realismo social, como Primer destino (1989) de Salvador García Jiménez. Sin embargo, las más de las veces los escritores pueden conceder algún protagonismo al personaje maestro o maestra dentro de historias en las que se trata el mundo rural, el caciquismo o la ideologización política de la pedagogía, en conexión última con la vieja novela galdosiana. Así, Andrés Berlanga en La gaznápira (I984), Ángel Ma Lera en Losolvidados (I955), o Jorge Ferrer-Vidal en Diario de Albatana (i967).

La narrativa infantil y juvenil, por otra parte, recoge habitualmente anécdotas académicas escuela, y en algunas narraciones no faltan apuntes de didáctica de la lengua y literatura. En estos relatos para receptores de corta edad se tiende a dar una visión positiva del reducto escolar y de la figura magisterial, tal y como se corrobora en títulos como, Cinco panes de cebada (I98I), un clásico del retrato realista de la escuela rural debido a Lucía Baquedano, o Elmaestro y el robot (I983) de José Antonio del Cañizo.

\footnotetext{
${ }^{2}$ Este artículo es el fruto de mi estancia de investigación durante el mes de julio de 2014 en la Universidad Autónoma de Madrid con la investigadora responsable Dra. Carmen Servén Díez. A ella le agradezco la generosa acogida que me brindó durante los 3 I días de la estancia. Debo reconocer asimismo que este trabajo se ha beneficiado de su colaboración intelectual.

3 Sobre los usos y costumbres de la escuela reflejados en la literatura ha insistido últimamente la crítica: Ezpeleta (2006), Lomas (2007 y 2008), Martínez Otero (2OIO). Más en particular, sobre la educación lectora y literaria en la narrativa, Ezpeleta (2008, 20II, 20I3a y 2OI3b).
} 
A partir de estas novelas, complementadas por algunos otros títulos, puede fijarse un corpus representativo de obras que permite la exploración de los usos docentes en los primeros niveles educativos, dentro de los cuales resultarán significativas algunas imágenes acerca de las enseñanzas de la Lengua o de la educación literaria de los escolares, pues es normal que los novelistas de las generaciones de posguerra y sus continuadores, al considerar aspectos educativos acuciantes como el de la alfabetización, esbocen entre líneas sus reflexiones didácticas. Recogemos en nuestro corpus novelas con argumentos fuertemente "pedagogizados" y que han sido publicadas entre I939 y 2005, pero que evocan una práctica escolar comprendida entre la época de la Segunda República y la antesala de la Democracia.

\section{2 - Los novelistas de posguerra evocan los años de escuela en época de Guerra y Re- pública}

Sobresalen en este apartado unas cuantas novelas que glosan los ideales educativos de la Segunda República, y en las que se imprime a la educación lectora y literaria por parte de los maestros, y muy especialmente las maestras, un sesgo innovador. A modo de preámbulo, hay que decir que las tres primeras décadas del siglo XX presentan asimismo estampas literarias, casi siempre muy tenues, en las que la cuestión de la alfabetización escolar es recordada de manera insatisfactoria, con maestros y maestras rutinarios cuando no ignorantes o autoritarios. Así, Rosa Chacel en Memorias de Leticia Valle (1945) evoca su aprendizaje infantil en el Valladolid natal en la primera década de siglo XX con maestros de escuela con sensibilidad artística, pero con una maestra de primeras letras ignorante. En Desde el amanecer (1972), por ejemplo, recuerda cómo las monjitas le enseñan versos de poco vuelo (75), cuentos de Calleja como "La cruz del diablo", o los Cuadernos de Julio Verne a través de una madre defensora de la pedagogía natural. Desde el exilio Arturo Barea, en La forja, primer libro de La forja de un rebelde (I94I-I944), evoca las duras enseñanzas infantiles de principios de siglo en las que la alfabetización se subordinaba a la disciplina: "Antes de aprender la letra se aprende a estar en fila callado. Luego se aprende a leer” (I2I). Vicente Soto hace lo propio en La zancada (Premio Nadal I966) y recrea el ambiente escolar de colegios privados en los años veinte, con la estampa del niño castigado a escribir I.5Oo una muestra (86), como práctica de expresión escrita que se repetirá en las escuelas de la posguerra.

Pero ciertamente el bloque de novelas y narraciones que contiene más riqueza de datos es el de la escuela republicana. Muy circunstancial es el relato del novelista gallego Eduardo Blanco Amor, en Aquella gente (1976, traducción del gallego Xente ao lonxe, I972) en el que evoca una experiencia de alfabetización a partir de los ideales educativos de la Primera República, a través de una escuela laica que promociona la biblioteca abier- 
ta al puebló . La escuela de la Segunda República sí que genera un ramillete de novelas femeninas en las que pasa a primer plano la figura de la maestra. La figura magisterial masculina aparece recreada por Honorio García Álvarez en la novela profesional pedagógica, Un republicano (1978). Explica el funcionamiento de la escuela mixta unitaria en los años veinte y el advenimiento de la escuela de la Segunda República con sus novedades pedagógicas: los juegos escolares naturales, las barracas de intelectuales con clase de alfabetización y demás aspectos culturales. Por su parte, Manuel Rivas en "La lengua de las mariposas” (I995), dentro de Qué me quieres, amor, insiste en la reformulación del personaje "maestro republicano" que tiene especial sensibilidad literaria y que practica una pedagogía natural del amor, al convertir en cuento fascinante todo lo que toca, haciendo valer el don de la oralidad como gran elemento didáctico, capaz de poner en contacto a los niños, por ejemplo, con la lírica medieval de aquellos poetas que "escriben canciones de amor en la Provenza y en el mar de Vigo" (I9) en el tránsito de la República a la Guerra Civil.

Las memorias de una maestra de raza como María Sánchez Arbós (Mi diario, 1999 [r989]) complementan la glosa de la pedagogía avanzada del momento que se desprende de novelas canónicas escritas por Dolores Medio y Josefina Aldecoa, en las que se alude a la coeducación y no falta el dibujo del currículo de primaria con las lecturas literarias. Este último aspecto queda de este modo recogido en el libro de Sánchez Arbós:

3o de agosto de 1935

En cada clase colocaremos 54 cuadernos con plumas, lápices, gomas, tizas blancas y de colores. También dejaremos en cada una 54 libros de lectura. Para las clases mayores, la Antología de prosistas castellanos de Menéndez Pidal. Las clases intermedias tienen Flor de leyendas, El conde Lucanor, la Ilíada y la Odisea. En las clases primeras leerán los Cuentos de Andersen y de Grimm, y los más pequeños, Muñecos y Medio Castilla. Está la escuela como nueva y con irresistible atractivo para habitarla y trabajar en ella gustosamente (I46).

En el fragmento correspondiente al testimonio de 30 de enero de 1936 comenta la aplicación a la escritura de la técnica Freinet:

Hemos escrito a Barcelona, pidiendo el envío del material necesario para la técnica Freinet. Los padres de la Asociación han pagado el gasto de 200 pesetas

\footnotetext{
${ }^{4}$ Benito Pérez Galdós también se había hecho eco en el episodio nacional La Primera República (I9II) de los anhelos innovadores de las maestras de la Primera República, con una visión humorística y ambigua sobre la capacidad real de transformación social, pues presentaba un cortejo de maestras con destino a Cartagena para poner en funcionamiento una escuela innovadora, pero caracterizadas con los rasgos peyorativos del estereotipo literario de la maestra de escuela. Doña Gramática era "una matrona un tanto maciza, con aire de institutriz o profesora de casa grande" (I23) o "una vieja pedante" que hace el amor a Tito. Y al narrador le resulta "insoportable la carcamurria pedantesca y el traqueteo gramatical de aquella buena señora” ( 140 ). Doña Caligrafía, por otro lado, es "una señora delgaducha algo ajada y canosa, natural de Cartagena" (I43)
} 
para introducir en la escuela esta Imprenta. Vamos a ensayar la imprenta en la escuela, y espero que resulte bien, aunque no es nuestra escuela, colmada de alumnos, semejante a la escuelita de Freinet en los Alpes (I57).

Con todo, anota cierto fallo de la pedagogía nueva en la ausencia de esfuerzo del niño (I58).

Como decimos, las dos novelas básicas que recrean la escuela republicana, con protagonismo de la maestra de primeras letras y con conexión de pedagogía y política, son Diario de una maestra (I993 [I96I]) de Dolores Medio y la Historia de una maestra (I990) de Josefina Aldecoa. La primera es una novela que relaciona esta nueva pedagogía con el modo educativo de la Institución Libre de Enseñanza. En un fondo de realismo social se confronta la vieja escuela frente a nueva, con explicación de la labor de las Misiones pedagógicas: libros, cuentos, novelas (II7). Adaptaciones escolares de escritores clásicos como Lope, Calderón, Tirso o Cervantes se entremezclan con autores más recientes como Machado, Juan Ramón Jiménez, Lorca, Casona o Alberti ${ }^{5}$. A la maestra la critican en el pueblo por jugar (I47) y por leer Platero y yo. Se alude a los métodos de la letra con sangre entra de la vieja maestra (I49), opuestos a la educación literaria propugnada por esta nueva maestra, que hace títeres en la escuela (I5O) o lee los cuentos de Bunin. Y es que su antecesora en el puesto, la señora Obaya, guardaba en el armario "viejos libros de lectura, con su moraleja, cuadernos y muestrarios de letra gótica y redondilla" (93).

Historia de una maestra (I990) de Josefina Aldecoa es otra novela plena que indaga en el sueño utópico de aquellos maestros republicanos. Se glosa igualmente la pedagogía nueva, la coeducación, y las misiones pedagógicas, en medio de la pobreza canónica del magisterio. No faltan apuntes de caciquismo y acosos a maestras, tan habituales en la novelística realista que explora la condición social de la docente. Con tasas de analfabetismo del treinta y dos por ciento, se potencian las clases de adultos. En la escuela se lee $E l$ Quijote y se comentan párrafos: “Acababa de pedir a los mayores sus comentarios sobre un párrafo del Quïote que habíamos leído, mientras los más pequeños copiaban el trabajo preparado en la pizarra” (I2O). Se pondera la biblioteca, formada por libros y periódicos (49): "Me conmovía profundamente cuando uno de mis niños decía: ¿Puedo usar la Biblioteca? Y le veía revisar ávidamente el montoncito de papel impreso que era un tesoro y sobre todo un símbolo de otros tesoros lejanos y difíciles de alcanzar” (49). La maestra, en fin, constata la bondad pedagógica del método de la lectura por la escritura: "Estoy empleando el método de la lectura por la escritura y me da buenos resultados" (32).

Ramiro Pinilla en Verdes valles, colinas rojas, Las cenizas de hierro (2005) da forma literaria a una historia de maestros humillados en tiempos de Guerra civil. La maestra Mercedes en medio del sufrimiento de la cárcel y del control ideológico de los falangistas se erige en defensora de la lengua vasca: "La señorita Mercedes tardó casi todo el mes de

\footnotetext{
5 Covadonga López Alonso señala, en nota a la edición de la novela, cómo Dolores Medio "se dedicó con entusiasmo a su labor docente, realmente innovadora, y cuidó, especialmente, la lectura. Sus alumnos recitaban poemas de Machado, Alberti y escenificaban a García Lorca” (II8).
} 
septiembre en persuadir a don Manuel de que su trabajo en la escuela no era el precio por su libertad sino un arma de resistencia. "No me limitaré a enseñar a mis niñas a escribir sin faltas de ortografía. Les hablaré en euskera, aunque sea un minuto”, le aseguró.” (94).

Por lo que respecta a la enseñanza religiosa, Elena Quiroga en Escribo tu nombre (I993 [I965]) rememora el internado docente femenino de las Ignacias (asimilado a los Jesuitas) en un tiempo inmediatamente anterior de "parones" escolares, motivados por el ambiente de violencia política en vísperas de Guerra Civil (I77). En medio de una enseñanza memorística, hay una valoración desigual por parte de la narradora acerca de la formación lectora que se promueve en ese colegio. Se insiste en la práctica de declamación, de redacción y de lecturas místicas como el Cántico Espiritual de San Juan de la Cruz; funciones de carácter religioso y exposiciones (357), con alusiones ocasionales a poetas contemporáneos (486).

\section{3 - Los años cuarenta y cincuenta}

Los años cuarenta se presentan como un periodo negro en el que la literatura se encuentra mediatizada por una censura que no admite con facilidad la disquisición sobre prácticas educativas. Y es que la guerra civil española supone un hito histórico con consecuencias literarias y también pedagógicas, plasmadas en lo que Agustín Escolano

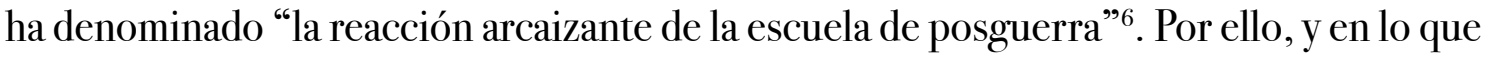
se refiere al material narrativo de autores significativos publicado en esa década, habrá que extraer entre líneas fragmentos en los que estos aspectos aparezcan tratados de modo tangencial.

Por un lado están los colegios privados y las academias preparatorias para el bachillerato en época de posguerra. Estos, por ejemplo, aparecen dibujados con tintes sombríos en La sombra del ciprés es alargada (I997 [I948]) de Delibes, con una lóbrega academia dirigida por un maestro de mezquinos horizontes donde se practican dictados y análisis gramaticales. Este mismo novelista, en Mi idolatrado hïo Sisí (I993 [I953]), esboza algunas líneas didácticas practicadas por los maestros a domicilio. Se trata de una anécdota narrativa en torno a la educación de un niño de seis años con un "tira y afloja" entre los padres que entienden de manera diferente los modos pedagógicos que han de aplicarse. Se alude en esa novela a los colegios de monjas en los que se enseña mediante abecedarios implacables (I37), pero se recrea la situación de los profesores particulares a domicilio. Entre los que dan lección al niño protagonista sobresale la Señorita Matilde, que encarna el prototipo de la maestra cursi y remilgada que insiste de forma obsesiva en el cuidado de la caligrafía (I83), pues “dibujaba primorosamente las letras" (I8I).

\footnotetext{
6 "Maestros mal pagados, a los que se les halagaba con el tópico de la vocación mientras se les sometía a la disciplina del sistema, oficiaban como actores dóciles las rutinas de la profesión y los papeles que les asignaban los nuevos tiempos. Una enseñanza de cartilla, catecismo y enciclopedia daba orden y contenido a la marcha de las clases" (Escolano, 2006: 273).
} 
Pero el grueso del conjunto narrativo recoge estampas del magisterio rural, para resaltar casi siempre las precariedades materiales y las insuficiencias didácticas. El docente masculino suele ser personaje episódico que surge habitualmente en tramas narrativas que van más allá de la temática escolar. Así, Lauro Olmo en el cuento "Tinajilla”, inserto en el libro de relatos Golfos de bien (I992 [ı968]), describe al maestro de escuela, don Ramón, como una mala persona, autoritaria, hosca y terrible: "Era el dos más dos, el cabo de Finisterre y el pluscuamperfecto de subjuntivo del verbo ser" (I42). Santiago Sancho Vallestín en una obra de 2003 (Siempre en el corazón. Memorias de un niño rural de posguerra: 1939-1949) evoca la práctica escolar rutinaria del maestro rural de primeras letras de los años cuarenta en condiciones de máxima precariedad:

En aquella barahúnda de gritos, lloros y mocos, todavía quedaba tiempo para ir descubriendo letras y palabras. Y aunque la única cartilla que en la escuela había, estaba tan desgastada que parecía escapársele las letras, aún lográbamos algunos conseguir comprender las aburridas frases de: mi mamá me ama; mi yaya no llora. A, E, I, O, U. Más sabe el borrico que tú. U, $O, I, E$, A. Si no rezas bien la Salve la Virgen no te querrá (I7).

Los cuentos de Luis Mateo Díez son testimonios ricos y sentidos de la experiencia escolar rural de la escuela de posguerra (años cuarenta y cincuenta) donde se confrontan modelos viejos frente a algunos atisbos de los nuevos, con la figura del maestro ajustada al estereotipo (vestimenta llamativa, castigos físicos, material escolar deficiente y situación social del maestro muy precaria). Con todo, hay en estos relatos un juicio más favorable hacia al maestro de primeras letras. Así, en Días del desván (200I [I997], "Las voces", 80-83) a pesar de presentar a Don Servo como un maestro clásico que atemoriza a los niños con la vara, hay lugar para una cierta educación literaria con cuentos a la lumbre:

La voz del maestro tenía en la lectura un tono más sosegado, como si se demorara en las frases para facilitar su comprensión y alargar aquellas historias que unían en el invierno, entre el clamor monótono de la lluvia y el rumor de la estufa, las desventuras del caballero andante, los ardides del pícaro o las habilidades de un náufrago remoto. Esa voz no era muy distinta de las voces nocturnas que entretenían las reuniones en las cocinas del Valle, cuando todas las labores estaban hechas y los vecinos concurrían con la paciencia de un ocio que podía demorarse hasta el aviso del sueño (82).

En el relato "La tiza" (IOI-IO3), el maestro sustituto don Arno sucede a la vara de Don Servo y convierte la tiza en instrumento lúdico para enseñar ahora a través de colores y dibujos. Los maestros de posguerra que pueden espigarse en los relatos de Ana María Matute (Algunos muchachos, I964) son percibidos asimismo con mayores dosis de 
benevolencia por la voz del narrador, con subrayado de cualidades humanas positivas, como el empeño de alfabetizar a domicilio a niños reticentes a frecuentar la escuela.

Vuelve a ser abundante la referencia literaria al personaje femenino que tiene a su cargo una escuela, casi siempre rural. Se genera una nueva situación educacional, de la que pueden encontrarse reflejos expresivos en alguna "novela para niñas" de los primeros años cuarenta, en las que se focaliza la escuela rural con personaje protagonista identificado con la ideología política resultante. Es el caso de Mari Sol, maestra rural (1944) de Josefina Álvarez de Cánovas?. De esta experiencia profesional de maestra se desprende la asociación de la misión docente a la del apostolado ${ }^{8}$. Se presenta aquí a una joven maestra, suficientemente preparada, que acepta a pies juntillas la retórica educativa del momento y que es capaz de alfabetizar con eficacia a sus alumnas. Les comunica a las escolares, además, el gusto por el canto y la tonada popular castellana en medio de alusiones continuadas a la poesía de Gabriel y Galán.

En la parte final de la novela, la maestra puede decir con satisfacción ante el inspector: "Cuando he llegado aquí casi todas eran analfabetas y se andaban en los Cristos, como decían ellas, las pobrecitas. Hoy saben casi todas leer, escribir, calcular y dibujar. Expresan ya por escrito sus sencillos pensamientos..." (I28).

En otra novela pedagógica profesional poco conocida, como es Maestra y mujer (I964) de Ma Carmen Martínez, se evidencia igualmente la aceptación plena de la retórica ideológico-religiosa del momento por parte de la maestra rural de posguerra (años cuarenta y cincuenta), con canto ingenuo a los valores de la vida rural al modo de las novelas de idilio, y con apuntes leves sobre educación literaria por medio ahora de composición y declamación en veladas de poesías lacrimógenas (capítulo cinco). En Viaje a la Alcarria (I97I[I948]) de Camilo José Cela, el narrador viajero se topa con maestras rurales que, aparte del fuerte contenido ideológico propio del momento, encarnan el paradigma del docente que sigue metodologías memorísticas que atentan contra la lectura comprensiva (I7I).

Xosé Neira Vilas en el clásico del realismo social, Memorias dun neno labrego (escrita en gallego y publicada por primera vez en Argentina en i96ı y en I98I, en España), apunta las duras condiciones de la Galicia rural de los años cuarenta, y otorga protagonismo a la joven maestra rural, la amorosa Eladia. Esta mejora las costumbres de un docente viejo, que pronuncia ante los niños discursos ininteligibles al modo de los viejos maestros galdosianos decimonónicos. Y es que en la novela de posguerra sigue siendo re-

\footnotetext{
7 Viñao Frago, que ha recuperado memorias y autobiografías de maestros de la España contemporánea, (20o9) aporta algunos otros títulos de esta literatura "femenina educativo-moralizadora" de la posguerra: Eterna colegiala (1958), de Carolina Corbera Fradera; Mi colegio (1959), de Pilar García Bravo o Diario de una maestrita rural (I963), de Julia García Fernández Castañón (Viñao Frago, 1999b: 227).

${ }^{8}$ Con más carga ideológica aún en época inmediatamente anterior, en medio del contexto convulso de la Guerra Civil, puede rastrearse la figura de la maestra en algunas novelas cortas insertas en colecciones falangistas como $\mathrm{La}$ novela del sábado. Aparece allí la figura de la maestra de escuela en plena contienda civil al grito de ¡Arriba España! Ver el libro de $\mathrm{M}^{\mathrm{a}}$ Ángeles Naval en el que se recogen las fichas de algunas de esas novelas, concretamente, la titulada, Mariquilla, barre y barre, de Cristóbal de Castro (II-nov-I939), o Héroes de otoño, de José Andrés Vázquez (9-dic-1939); (Naval, 2000: I6r y I64).
} 
currente la configuración del "maestro de escuela” ajustado al estereotipo costumbrista con fuerte connotación negativa, caracterizado entre otros rasgos por el de la pedantería, asociada al habla aquejada de lo que podría llamarse "gramaticalismo".

Las experiencias docentes de los maestros de los años cincuenta siguen un patrón parecido a los de la década anterior. Y es que los cincuenta siguen siendo "años de hierro", como testimonia gráficamente Juan Eslava Galán en su novela con un protagonista adulto que rememora, al modo de la novela picaresca, el cambio de colegios religiosos en las primeras edades escolares (Escuela y prisiones de Vicentito González, 2000) ${ }^{9}$. Del hilvanado de cuadros que caracterizan la escuela franquista se desprende una impugnación de los aprendizajes memorísticos y se anota la incuria intelectual de los maestros. Aparecen los internados precarios de los años cincuenta (también de los sesenta), con maestros que leen a escondidas a Marcial Lafuente Estefanía. En medio de tales deficiencias, el autor observa con simpatía, en el capítulo segundo, al "maestro republicano" que se esfuerza por dar a leer a los niños a Galdós, Baroja, Unamuno y Blasco Ibáñez. Pero predomina en esta novela la estampa de maestros identificados con la nueva situación, como Don Raimundo Girón, al que le correspondió una plaza en el pueblecito "Navas del Prior" por el turno de las “oposiciones patrióticas":

Los alumnos estudiábamos o copiábamos cien veces una muestra que Lupiáñez escribía en la pizarra, por lo general sacada de palabras de José Antonio: España es una unidad de destino en lo universal. (...) También aprendíamos de memoria poesías y las recitábamos. Algunas eran largas como la Oda al Concilio Vaticano I o La conversión de los mártires del Japón o la del Dos de Mayo de Bernardo López, pero otras eran más cortitas y fáciles como el Saludo a Franco $\left(55^{-56}\right)$.

Javier Gracia Gimeno en La niebla del olvido (2007) presenta la figura de un maestro que, en los años cincuenta, mantuvo una actitud pedagógica valiente en un pueblo del Pirineo. Pero se trata de una excepción, tal como se refleja en esa misma novela la postura del maestro sustituto, don Acacio:

"Libro y pizarra, lápiz y cuaderno. Lo demás son tonterías y ganas de perder el tiempo", sentenciaba don Acacio (...) aquel bruto lo primero que había hecho fue advertirle que a la escuela se venía a enseñar a leer y las cuatro reglas y Geografía...; pero que de política, ni palabra. Que en su escuela se empezaba la jornada cantando el Cara el sol y se terminaba leyendo un capítulo de Héroes de la Cruzada (IIO y IO2).

\footnotetext{
9 Esta narración es reformulación, según se desprende del artículo de Abril Palacios (2OOO: IO2-IO3), de la primera novela juvenil del autor, Juan Eslava Galán, Tu magistral amor (I969).
} 
Juicio parecido aporta el escritor Agustín Fernández Paz cuando rememora su experiencia escolar como niño en los finales años cincuenta: “Una escuela en la que todavía escribíamos con pizarra y pizarrín. También escribíamos en el cuaderno, sobre todo en la clase de los mayores, con lápiz o con la pluma que había que mojar con cuidado" (2008: 85). Y remata: "Un único libro de texto y unos cuantos libros de lectura, viejos y gastados, encerrados en un armario acristalado. De uno de ellos había ejemplares repetidos y en él leíamos en voz alta casi todas las tardes. Se llamaba Escudo Imperial' (85). Modos pedagógicos análogos se reproducen en relatos de época como Martín de Caretas en el pueblo (1972 [1958]) de Sebastián Juan Arbó:

\begin{abstract}
Martín andaba muy ajeno a lo que ocurría, ocupado con todo su ánimo en trazar unas letras; siempre le quedaban mal (...). Martín se volvió asustado, sin saber qué sucedía. Precisamente aquella mañana había trabajado con aplicación, con la lengua fuera, esforzándose en dibujar letras lo mejor que podía. No le valía. Camándulas estaba allí, de pie, mudo, señalándole con la vara el cartapacio en el suelo (2O).
\end{abstract}

En esos mismos años cincuenta Ángel Ma Lera en Los olvidados (2004 [1957]) presenta una experiencia testimonial en la que cobra protagonismo la figura del maestro anarquista, como continuación de las estampas de autores de principios de siglo $\mathrm{XX}^{10}$, que extiende por los pobladores adultos de las chabolas de una zona marginal una educación en la que se mezcla la teoría y la vida. Enseña gramática y pondera las lecturas de Galdós, Hoyos, Trigo, Zamacois: “Antonio conocía bien todo esto. Ahora tenía que entrar en su chabola para preparar el quinqué, los lápices y los cuadernos. Pronto vendrían Emilio y sus otros tres discípulos y tendría que enseñarles gramática” (190).

A pesar de las severas restricciones a las que se ve sometida la maestra rural, esta puede evitar ser superada por el ambiente, e incluso puede transmitir estímulos para la formación lectora de los escolares. Carlos Castán en "Una isla" (2004) rememora a doña Adela como "un paréntesis de delicadeza en medio de la tosquedad de un pueblo que braceaba sin demasiadas fuerzas buscando la salida de una posguerra interminable" (49) que logró enseñar a los niños "que en cualquiera de los tinteros abiertos sobre el pupitre vivían como dormidas todas las palabras de mundo" (50). Se trata de una maestra que mejora a su antecesora, pues ahora "los niños ya no aprendían más himnos triunfales, sólo canciones de corro, el patio de mi casa y todas esas cosas, tonterías para saltar a la cuerda o poesías sobre las estaciones del año, versos de flores y de pájaros" (50). Francisco Candel, por su parte, en Pueblo (I96I), capta a modo de reportaje la precariedad de la escuela

\footnotetext{
Io De manera episódica aparecen personajes maestros en novelas de los primeros años del siglo XX con un perfil de anarquista o comunista, estimulados a la entrega altruista por el bien de la humanidad, cercanos a los más desfavorecidos. Así, Baroja en Aurora roja (I9O4) o Blasco Ibáñez en La bodega (I9O5).
} 
rural de los finales cincuenta (232-239), con glosa de una pedagogía que consiste en el repaso de la lección y las preguntas orales y con el subrayado de alguna expansión lúdica por medio de los juegos de momos.

El ejercicio de la profesión de maestra en el exilio tampoco resulta fácil, tal como atestigua Josefina Aldecoa en la novela continuadora de Historia de una maestra. En efecto, en Mujeres de negro (I994) la protagonista ejerce en escuela privada porque ha perdido su plaza por ideas políticas ${ }^{\mathrm{II}}$. Su hija testimonia la subsistencia difícil y aporta algunos datos acerca de las capacidades pedagógicas de la madre, también acerca de la educación literaria transmitida a los niños escolares de México: "Allí colocó los libros que más usaba: Platero y yo, Poesía infantil recitable, Países y mundos, los restos del naufragio. Cuando la clase empezaba y los niños la rodeábamos, mi madre empezaba a hablar y el torrente de sus palabras se extendía ante nosotros como un gran tapiz” (I2). Se señala, por ejemplo, que los chicos mexicanos leían mucho las novelas de Rafael Pérez y Pérez (95).

\section{4-Años sesenta y tardofranquismo}

Los primeros años sesenta suponen cierta continuidad con la situación anterior, tal como refleja la novela de Andrés Berlanga, La gaznápira (I984), de la que desprende una mirada panorámica del magisterio rural masculino de los años sesenta, con apreciaciones asimismo sobre la escuela anterior a través de cortes fragmentarios que evocan los finales de los cuarenta y de los cincuenta. Ahí sigue estando el buen maestro en medio del páramo. El contexto no deja de propiciar una educación que carga las tintas en la religión, con lecciones de memoria absurdas. No falta uno de los motivos recurrentes en este tipo de literatura, como es el "expediente al maestro" o la inauguración de biblioteca como logro del Régimen ${ }^{\mathrm{I}}$. El maestro don Salustiano utiliza el plumillero, el tintero de loza y practica una pedagogía "de corro".

Salvador García Jiménez en Primer destino (I989) traspone una experiencia profesional que podría calificarse de canónica, localizada asimismo en los mediados sesenta. En ella se explica el funcionamiento de la escuela unitaria en un pueblo perdido. Ambiente opresivo, muchos alumnos, fatigosa faena burocrática, mediatización caciquil y clerical, inspección latosa, precariedad y dificultades de convivencia del maestro. El autor, que vindica su primera experiencia magisterio, describe los malabarismos que tiene que hacer para enseñar cantando a los párvulos (ra, re, ri, ro...), sirviéndose de alumnos ayudantes para lograr avances del grupo entero en lectura y escritura. Eso sí, la nueva maestra interina recién llegada comete faltas de ortografía.

\footnotetext{
II Sobre la depuración y represión de maestros durante la dictadura franquista pude acudirse como obra básica reciente al libro de Antonio Sánchez Cañadas (2007).

I2 María Nieves Gómez García señala cómo los niños y las niñas de los años sesenta viven en un país que está cambiando (la televisión y la emigración actúan como agentes de transformación). "Sin duda el modelo de enseñanza estaba cambiando, aunque todavía ese cambio no afectase esencialmente al objetivo final de la educación propuesta. La escuela de los años sesenta estaba prendida todavía de los principios del Movimiento Nacional, aunque maestros y escolares empiecen a sentirse incómodos con el uso de sus rituales en otro tiempo indiscutibles" (2006: 337-338).
} 
Francisco Candel en Viaje al Rincón de Ademuz (I977) constata ya cómo a finales de los sesenta y principios de los setenta las escuelas se van quedando progresivamente sin alumnos, con pincelada costumbrista de tertulias de los maestros con fuerzas vivas. José Antonio del Cañizo en un clásico de la literatura juvenil como $E l$ maestro y el robot (2006 [ig83]) focaliza humorísticamente la labor del maestro rural en momentos de cambio en los primeros años setenta (Ley Villar Palasí): la transición al modelo educativo "tecnocrático", tan bien estudiada en la tesis doctoral de Olga Roig López (2OO2). Se opone el primitivismo de las escuelas unitarias a los nuevos modos, que dan carta de naturaleza a las tablas, los gráficos, la teoría de conjuntos y los análisis sintácticos (59). Con todo, se anotan en el haber del maestro "de toda la vida" prácticas encomiables como la invitación a la lectura de obras como El libro de la selva, El Conde

\section{Lucanor o Las aventuras de Tom Sawyer.}

Vuelve a ser muy representativo el material narrativo sobre la maestra rural que, también en los años sesenta, aparece abocetada en contextos de precariedad social, con reflexiones de las voces editoriales de las novelas a propósito del callejón sin salida en el que se encuentran las docentes. Así, Las hogueras (r964) de Concha Alós es una novela realista ambientada en los primeros sesenta en un rincón paradisíaco de la Mallorca rural. La protagonista es la maestra Asunción Molino que arrastra una vida rutinaria que complementa su sueldo con enseñanza de español para extranjeros. Da clases de adultos y los alfabetiza con "métodos morunos" mediante la técnica del deletreo, en medio del tedio, la soltería y la falta de vocación: “-A ver, Fulgencio. Aquí. Lee (...) Ma, me, mi, mo, mu. Mi mamá me mima $(26)^{\mathrm{r} 3}$.

De forma análoga Jorge Ferrer-Vidal, en su Diario de Albatana (I967), insiste en la descripción del ambiente rural asfixiante, en los mediados sesenta, con una maestra, Mesalina ${ }^{\mathrm{I} 4}$ rediviva, sumergida en ambiente caciquil e incapaz de vencer el determinismo inexorable que se cierne, tanto sobre su propia persona como sobre los sufridos escolares. Ella "se resigna a enseñar a leer a sus barbianes (...) mientras los niños cantan las últimas estrofas (62).

Santiago Lorén en El pantano (I967) insiste en el retrato escolar realista de los años centrales de los sesenta con caracterización estereotipada de personajes. Es localidad grande que tiene notario y, aunque de forma episódica, aparece la maestra, caracterizada negativamente, ejemplificando en el relato la falta de acoplamiento entre

\footnotetext{
I3 Una mirada irónica a propósito de la alfabetización de adultos de los años sesenta aparece en Los santos inocentes (I98I) de Delibes en el episodio de alfabetización que impartieron dos señoritos venidos de Madrid, al presentar un simulacro de instrucción mediante caprichosas uniones de las letras, como remedo del viejo método del deletreo. Para Antonio Viñao Frago, " "pocos textos resumen mejor (que el contenido en esta novela de Delibes) la naturaleza de la tradicional alfabetización escolar. Una alfabetización basada en la consideración mágica de la palabra escrita que se aprende, y a la vez se impone, desprovista de sentido o con un único sentido canónicamente prescrito" (I999a:I27).

I4 Salvando las distancias, existe algún parecido de esta novela con Doña Mesalina (I9Iо), de López Pinillos, con maestra protagonista femenina. López Pinillos presenta un contexto escolar en el que esta maestra se acoge a las metodologías teóricas poco eficaces para la enseñanza de las primeras letras ("No, no, Antonia, Orfandad, sin hache. Huérfano la lleva tan sólo por preceder al diptongo $u e$, según una regla ortográfica adoptada antiguamente para indicar que la $u$, que entonces representaba al sonido de $u$ (vocal) y de $v$ (consonante) debía pronunciar con vocal en tales palabras", 84).
} 
la escuela y las fuerzas vivas, tal como se demuestra en la sesión poética celebrada al final de la novela. Por su parte, Bernardo Atxaga en Obabakoak (r997) evoca las malas condiciones de la escuela y la soledad de una joven maestra rural y asocia la formación lectora con la Enciclopedia difícil de Dalmau (75).

Antón Castro en "Mujeres del cuadro" (2004) recuerda con más afecto a su maestra primera, conocedora de idiomas, que cuenta cuentos del país en la Galicia rural de finales de los sesenta en aulas que tienen pupitres aún con tintero. Todo un clásico del retrato de la escuela rural, en fin, es la novela de Lucía Baquedano, Cinco panes de cebada (I98I), leída como literatura infantil y juvenil. Se trata de un Bildungsroman en el que la lucha por el afianzamiento de una vocación profesional, en medio de las hostilidades del ambiente, sirve para señalar la maduración del personaje principal, maestra. Se glosa al modo realista la dura condición social de la joven maestra rural en los años sesenta, con subrayado de la confrontación entre los usos y costumbres rurales y la aspiración a una cómoda vida urbana por parte de las nuevas generaciones. En el haber de esta maestra protagonista ha de anotarse el esfuerzo por hacer de la biblioteca escolar un lugar vivo de aprendizaje.

\section{5-Conclusión}

La exploración del conjunto narrativo aquí considerado arroja imágenes expresivas sobre la alfabetización y educación literaria de aquellas generaciones que estuvieron escolarizadas entre la Segunda República y el fin de la Dictadura de Franco (con alguna breve consideración sobre la escuela de las tres primeras décadas de siglo XX). Buena parte de estas novelas se adscriben a la corriente del Realismo social, por lo que sus autores suministran una visión panorámica de usos didácticos que tienen que ver con la enseñanza de las primeras letras en un contexto de penuria, en medio de injusticias, con predominio del marco rural.

En cuanto a las propuestas didácticas que se desprenden, destacan en primer lugar algunas novelas que plasman los ideales educativos de la Segunda República. En ellas se pondera la educación lectora y literaria impulsada por los maestros, especialmente por las maestras, pues absorben en su práctica docente las ideas pedagógicas innovadoras, como el método de la lectura por la escritura, la técnica de Freinet o el fomento de lecturas literarias motivadoras.

El núcleo narrativo que evoca la escuela de los años cuarenta alude, por un lado, a las academias y colegios privados, donde imperan el memorismo, los "alfabetos implacables" y el prurito ortográfico; y por otro lado, la escuela rural, aquejada de insuficiencias tanto materiales como didácticas, con cartillas desgastadas, enciclopedias, cantos patrióticos, copias mecánicas de textos y, excepcionalmente, algún tipo de prácticas literarias que fluctúa entre los cuentos populares narrados por maestros y maestras con algunas dosis de sensibilidad y las declamaciones de poesías lacrimógenas en actos académicos impostados. 
Las didácticas de los maestros de los años cincuenta siguen maneras parecidas a las de la década anterior. Copias de muestras de texto en número desorbitado, repaso de la lección a través de preguntas orales, aunque con algunos atisbos ahora de enseñanzas lúdicas, como la práctica de los juegos de momos, o la constatación de la presencia de algún maestro "nuevo" que emite guiños didácticos al sueño pedagógico republicano, a la vez que aparecen en las narraciones algunos maestros comprometidos que alfabetizan a la población adulta.

La escuela de los años sesenta es evocada en un número considerable de narraciones, en las que el mundo rural suele funcionar como telón de fondo de las historias, con personajes docentes que pueden anotar críticamente situaciones de injusticia o pueden cuestionarse críticamente el sentido de su propia profesión. Aun así, buena parte de los maestros y las maestras suelen seguir inercias del pasado en cuanto a la didáctica de la lengua, pues la población rural se muestra más reticente a los cambios que en esta época se empiezan a producir en España. Eso sí, los atisbos de enseñanzas lúdicas anteriores se hacen ahora más evidentes en evocaciones de algunos escritores que recuerdan de forma más amable a sus maestros de primeras letras.

En fin, la narrativa que rememora la época del tardofranquismo glosa expresivamente la definitiva sustitución de la escuela "ideológica" por la "tecnocrática", con la desaparición de cartillas y enciclopedias y la valoración de la biblioteca escolar. 


\section{Referencias}

NOVELAS

- Aldecoa, J. (I990). Historia de una maestra. Barcelona: Anagrama.

- Aldecoa, J. (I994). Mujeres de negro. Barcelona: Anagrama.

- Alós, C. (I964). Las hogueras. Barcelona: Planeta.

- Álvarez de Cánovas, J. (1944). Mari Sol, maestra rural. Madrid: Magisterio Español.

- Antón Castro (2004). "Mujeres del cuadro”, en AA.VV. Maestras. Zaragoza: Prames, 57-6o.

- Atxaga, B. (i997). Obabakoak. Barcelona: Ediciones B.

- Baquedano, L. (2002 [198I]). Cinco panes de cebada. Madrid: S.M..

- Barea, A. (2007 [I94I-I944]). La forja, en La forja de un rebelde. Barcelona: Debolsillo.

- Baroja, P. (1998 [1904]). Aurora roja, Obras Completas, Trilogías II. Edición de José-Carlos Mainer Barcelona: Círculo de Lectores.

- Berlanga, A. (i994 [i984]). La gaznápira. Prólogo de Manuel Seco. Madrid: Espasa-Calpe.

- Blanco Amor, E. (1976). Aquella gente. Barcelona: Seix Barral. Primera edición en gallego (1972). Xente ao lonxe. Vigo: Galaxia.

- Blasco Ibáñez, V. (1998 [1905]). La bodega. Edición de Francisco Caudet. Madrid: Cátedra.

- Candel, F. (r96r). Pueblo. Barcelona: Destino.

- Candel, F. (1977). Viaje al rincón de Ademuz. Barcelona: Plaza y Janés.

- Cañizo, J. A. del (2006 [1983]). El maestro y el robot. Madrid: S.M.

- Castán, C. (2004). “Una isla”, en AA.VV. Maestras. Zaragoza: Prames, 49-5².

- Castro, C. (I de noviembre de 1939). Mariquilla, barre, barre... La Novela del Sábado.

- Chacel, R. (1985 [1945]). Memorias de Leticia Valle.Barcelona: Seix Barral.

- Chacel, R. (ig86 [i972]). Desde el amanecer. Barcelona: Seix Barral.

- Cela, C. J. (г97 [1948]). Viaje a la Alcarria. Barcelona: Destino. 
- Corbera Fradera, C. (1958). Eterna colegiala. Madrid: Lincor.

- Delibes, M. (I997 [1948]). La sombra del ciprés es alargada. Barcelona: Destino.

- Delibes, M. (1993 [1953]). Mi idolatrado hïo Sisí. Barcelona: Destino.

- Delibes, M. (198I). Los santos inocentes. Barcelona: Planeta.

- Eslava Galán, J. (200o). Escuelas y prisiones de Vicentito González. Barcelona: Muchnik Editores.

- Ferrer-Vidal, J. (1967). Diario de Albatana. Barcelona, Buenos Aires México, DF., Bogotá: Plaza Janés Editores.

- García Álvarez, H. (1978). Un republicano. Novela histórica. León: Gráficas Celaraya.

- García Bravo, P. (I959). Mi colegio. Madrid: Escélicer.

- García Fernández Castañón, J. (1963). Diario de una maestrita rural. Madrid: Escuela Española.

- García Jiménez, S. (2005 [1989]). Primer destino. Murcia: Nausicaa.

- Gracia Gimeno, J. (2007). La niebla del olvido. Zaragoza: Mira Editores.

- Juan Arbó, S. (1972 [1958]). Martín de Caretas en el pueblo. Madrid: Espasa-Calpe.

- Lera, Á. Ma . (2004 [1957]). Los olvidados. Edición de Asunción Castro Díez. Madrid: Castalia.

- López Pinillos, J. (г975 [г9го]). Doña Mesalina, edición de José-Carlos Mainer, Madrid, Turner.

- Lorén, S. (1967). El pantano. Barcelona, Buenos Aires México, DF., Bogotá: Plaza Janés Editores.

- Martínez López, Ma C. (I964). Maestra y mujer. Toledo: Imprenta López Menor.

- Mateo Díez, L. ([i997] 200I). Días del desván. Edición de Miguel Díez R. Madrid: Anaya.

- Matute, A. Mª (I982 [i964]). Algunos muchachos. Barcelona: Destino.

- Medio, D. (r993 [r96r]). Diario de una maestra. Edición de Covadonga López Alonso. Madrid: Castalia, Instituto de la Mujer. 
- Neira Vilas, X. (198і [196і]). Memorias dun neno labrego. Buenos Aires: Edicións do Castro.

- Olmo, L. (I992 [i968]). “Tinajilla”, en Cuento español de Posguerra. Antología. Edición de Medardo Fraile. Madrid: Cátedra, I4I-I43.

- Pérez Galdós, B. (г980 [г9гі]). La Primera República. Madrid: Alianza Hernando.

- Pinilla, R. (2005). Verdes valles, colinas rojas, Las cenizas de hierro. Barcelona: Tusquets Editores.

- Quiroga, E. (1993 [1965]). Escribo tu nombre. Madrid: Espasa Calpe.

- Rivas, M. (I999 [1995]). La lengua de las mariposas. Medrid: Alfaguara.

- Sánchez Arbós, M. (r999 [r989]). Mi Diario. Zaragoza: Caja de Ahorros de la Inmaculada y Gobierno de Aragón.

- Sancho Vallestín, S. (2003). Siempre en el corazón. (Memorias de un niño rural de posguerra: 1939-1949). Zaragoza: Editorial Comuniter.

- Soto, V. (I968 [i966]). La zancada. Barcelona: Destino.

- Vázquez, J. A. (9-dic-1939). Héroes de otoño. La Novela del Sábado.

\section{OTRAS REFERENCIAS}

- Abril Palacios, F. (2000). "Jaén en la narrativa de Juan Eslava”. Boletín del Instituto de Estudios Giennenses, I75, 93-Іо8.

- Escolano Benito, A. (2006). "Las culturas escolares en el último medio siglo”, en A. Escolano (dir.), Historia ilustrada de la escuela en España. Madrid: Fundación Germán Sánchez Ruipérez, $267-287$.

- Ezpeleta, F. (2006). El profesor en la literatura. Pedagogía y educación en la narrativa española. Madrid: Biblioteca Nueva.

- Ezpeleta, F. (2008). "Leer y escribir en la narrativa realista española". Ocnos: Revista de Estudios sobre Lectura, 4, 57-68.

- Ezpeleta, F. (2OII). "La formación del lector como tema en la última narrativa infantil y juvenil”. Ocnos: Revista de Estudios sobre Lectura, 7, IOI-IIO.

- Ezpeleta, F. (2013a), "Educación literaria en los colegios de las novelas (i94O-2010)", Quaderns de Filologia. Estudis literaris, I8, I47-I6I. 
- Ezpeleta, F. (20I3b). "Educación literaria en las novelas de colegios de la Edad de Plata". Alabe 8. [www.revistaalabe.com].

- Fernández Paz, A. (2008). "Los paisajes de la memoria”, en C. Lomas (coord.). Textos literarios y contextos escolares. La escuela en la literatura en la escuela. Barcelona: Graó, 83-IOO.

- Gómez García, Ma . N. (2006). "La infancia escolarizada: un proceso contradictorio”, en A. Escolano (dir.), Historia ilustrada de la escuela en España. Madrid: Fundación Germán Sánchez Ruipérez, 33-350.

- Lomas, C. (2007). Érase una vez la escuela: los ecos de la escuela en las voces de la literatura. Barcelona: Grao.

- Lomas, C. (coord.). (2008). Textos literarios y contextos escolares. La escuela en la literatura en la escuela. Barcelona: Graó.

- Martínez-Otero, V. (20IO). Literatura y educación. Madrid: Editorial CCS.

- Naval, Ma Á. (2000). La Novela de Vértice y La Novela del Sábado. Madrid: CSIC.

- Roig López, O. (2003). La institución educativa española desde la postguerra hasta la transición. Iglesia y tecnología [http:www.tdx.cat/bitstream/handle/ıo8o3/5424/ormide2.

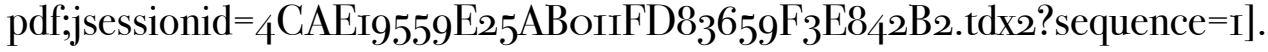

- Sánchez Cañadas, A. (2007). Memoria y dignidad. Depuración y represión del magisterio almeriense durante la dictadura del General Franco. Sevilla: Editorial Corduba.

- Viñao, A. (I999a). Leer y escribir. Historia de dos prácticas culturales. México: Educación, voces y vuelos, I.A.P.

- Viñao, A. (r999b). "Las autobiografías, memorias y diarios como fuente histórico-educativa: tipología y usos”. Sarmiento, 3, 223-253.

- Viñao, A. (2009). "Autobiografías, memorias y diarios de maestros y maestras en la España contemporánea”. Cultura escrita y sociedad, 8, I83-200. 